\title{
Blood pressure control and vascular protection with a fixed-dose combination of lisinopril + amlodipine + rosuvastatin in hypertensive patients
}

Sergey V. Nedogoda, Elena V. Chumachek, Alla A. Ledyaeva, Vera V. Tsoma, Alla S. Salasyuk, Victoria O. Smirnova, Victoria Yu. Hripaeva, Roman V. Palashkin, Ekaterina A. Popova

\begin{abstract}
Department of Therapy and Endocrinology, Volgograd State Medical University, Ministry of Healthcare of the Russian Federation, Volgograd 400066, Russian Federation.
\end{abstract}

\begin{abstract}
Correspondence to: Dr. Sergey V. Nedogoda, Department of Therapy and Endocrinology, Tsiolkovskogo str, 1, Volgograd 400001, Russian Federation. E-mail: nedogodasv@rambler.ru
\end{abstract}

How to cite this article: Nedogoda SV, Chumachek EV, Ledyaeva AA, Tsoma VV, Salasyuk AS, Smirnova VO, Hripaeva VY,
Palashkin RV, Popova EA. Blood pressure control and vascular protection with a fixed-dose combination of lisinopril + amlodipine + rosuvastatin in hypertensive patients. Vesse/ Plus 2018;2:37. http://dx.doi.org/10.20517/2574-1209.2018.36

Received: 23 May 2018 First Decision: 27 Aug 2018 Revised: 26 Sep 2018 Accepted: 1 Oct 2018 Published: 6 Nov 2018

Science Editor: Alexander D. Verin Copy Editor: Cui Yu Production Editor: Zhong-Yu Guo

\begin{abstract}
Aim: Assessment of the possibility of the fixed-dose combination of lisinopril + amlodipine + rosuvastatin (Equamer) to achieve further angioprotection in patients with arterial hypertension and high pulse wave velocity (PWV) despite the previous combination antihypertensive therapy (AHT).
\end{abstract}

Methods: The 24-week open-label multi-center observational study involved 60 patients who received dual combination AHT for 6 months. All patients underwent $24 \mathrm{~h}$ blood pressure (BP) monitoring, applanation tonometry (determination of the augmentation index and central BP), measurement of the pulse wave velocity and laboratory tests [blood lipids, fasting glucose test, homeostasis model assessment of insulin resistance (HOMA-IR), leptin, ultra-sensitive C-reactive protein (us-CRP)] before and after switching to the fixed-dose combination of lisinopril + amlodipine + rosuvastatin (Equamer).

Results: According to the office BP measurements, switching the patients from the dual combinations to the fixed-dose combination of lisinopril + amlodipine + rosuvastatin has resulted in a further decrease of $14.3 \%$ in systolic BP (SBP) and $18.5 \%$ in diastolic BP (DBP). According to the $24 \mathrm{~h} \mathrm{BP}$ monitoring data, the SBP has decreased by $16.1 \%$ and the DBP by $21.8 \%$. The combination of lisinopril + amlodipine + rosuvastatin has reduced the SBP by $14.4 \%$, the augmentation index by $14.5 \%$ and the central SBP by $8.1 \%(P<0.01 \mathrm{vs}$. baseline). The fixed-dose combination of lisinopril + amlodipine + rosuvastatin has provided a $44 \%$-decrease in low-density lipoproteins, a $36.1 \%$-decrease in triglycerids and a $10.3 \%$-increase in highdensity lipoproteins $(P<0.01 \mathrm{vs}$, baseline). The use of the fixed-dose combination of lisinopril + amlodipine + rosuvastatin has provided a definite decrease in the insulin resistance, as well as levels of us-CRP and leptin.

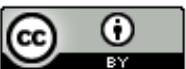

(C) The Author(s) 2018. Open Access This article is licensed under a Creative Commons Attribution 4.0 International License (https://creativecommons.org/licenses/by/4.0/), which permits unrestricted use sharing, adaptation, distribution and reproduction in any medium or format, for any purpose, even commercially, as long as you give appropriate credit to the original author(s) and the source, provide a link to the Creative Commons license, and indicate if changes were made.

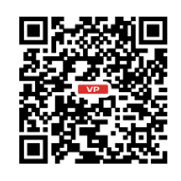


Conclusions: The fixed-dose combination of lisinopril + amlodipine + rosuvastatin provides improved BP control, better vessel elasticity indicators (augmentation index, PWV, central BP), boosts the lipid and carbohydrate metabolism and helps to reduce the inflammation and leptin resistance in patients who initially received a dual combination AHT.

Keywords: Arterial hypertension, pulse wave velocity, central blood pressure, augmentation index, leptin, inflammation, combination antihypertensive therapy, lisinopril, amlodipine, rosuvastatin

\section{INTRODUCTION}

Analysis of trends in the development of the modern concept of reduction in cardiovascular risk and mortality reveals several important directions.

First, there is a trend today to "tighten" the blood pressure $(\mathrm{BP})^{[1]}$ and lipid ${ }^{[2]}$ targets, which should lead to a further reduction in total and cardiovascular mortality in patients with arterial hypertension (AH) and atherosclerosis. Second, the co-relation of the improved indicators of elasticity of different caliber vessels, survival rate, and reduced risk of cardiovascular complications of AH can now be considered proven ${ }^{[3]}$. Principal differences have been found among the classes of antihypertensive drugs in the angioprotective effect (influence on the augmentation index, central systolic and pulse pressure) and, ultimately, in the influence on the typical end points (total and cardiovascular mortality, stroke, myocardial infarction) ${ }^{[4,5]}$. The same refers to individual representatives of antihypertensive classes ${ }^{[6-13]}$ and various combinations of antihypertensive drugs ${ }^{[14-16]}$. It has been shown that, upon achievement of the same BP level, lower mortality occurs in the hypertensive patients with a decreased pulse wave velocity (PWV $)^{[17]}$. Third, low-intensity noninfectious inflammation becomes an important and independent target of pharmacotherapy ${ }^{[1-20]}$, because its reduction [first of all, in ultra-sensitive C-reactive protein (us-CRP)] allows not only to reduce the risk of cardiovascular complications, but also to solve the problem of vascular comorbidity ${ }^{[2]}$. Fourth, there is a growing awareness that polypill is not only an opportunity to increase the patient's medication adherence by reducing the number of tablets taken, but also an effective multi-target pharmacotherapy option intended to achieve the BP and lipid targets ${ }^{[22]}$ and hence maximally reduce the risk of cardiovascular complications.

In this respect, it would be practically important to assess the possibilities of a fixed-dose combination of antihypertensive drugs with statins to provide a more pronounced angioprotection, to achieve the BP and lipid targets and to suppress the inflammation in those hypertensive patients who previously underwent a combination antihypertensive therapy (AHT).

The aim of this study was to assess the possibility of the fixed-dose combination of lisinopril + amlodipine + rosuvastatin (Equamer, "Gedeon Richter") to achieve further angioprotection in patients with AH and high PWV despite the previous combination AHT.

\section{METHODS}

The purpose of the study was to assess changes in the indicators characterizing the elasticity of different caliber vessels [PWV, wave reflection index (AI), central BP (CBP), intima-media thickness of the common carotid artery, flow-dependent vasodilation], insulin resistance and inflammation after switching the patients from the two-component antihypertensive combinations to the fixed-dose combination of lisinopril + amlodipine + rosuvastatin. The target was considered to be $\mathrm{BP}<140 / 90 \mathrm{mmHg}$.

The open-label study included patients who met all of the following criteria: age from 18 to 65 years, previous combined AHT conducted for at least 6 months, PWV above $10 \mathrm{~m} / \mathrm{s}$, age-standardized; signed informed consent of the patient to participate in the study. 
Patients with at least one of the following criteria could not be involved in the study: increased sensitivity to angiotensin-converting enzyme inhibitors (ACEI), angiotensin receptor blockers (ARBs), calcium antagonists (CAs) and hydrochlorothiazide; instable angina, recent myocardial infarction less than 1-monthold, cardiogenic shock, clinically significant aortic stenosis; decompensated heart failure; severe AH (BP above $170 / 100 \mathrm{mmHg}$ ) that requires a 3-component combination AHT, severe comorbidities; alcohol abuse, pronounced impairments of the kidney function (level of creatinine in the blood 2 times higher than the upper normal limit), liver function (activity of alanine and aspartate aminotransferases in the blood 2 times higher than the upper normal limit); malignant neoplasms; pregnancy or lactation; inability to understand the essence of the programme and give informed consent to participate therein.

The study involved 60 patients ( 26 men and 34 women, mean age $55.2 \pm 6.5$ years and body mass index $\left.28.8 \pm 4.6 \mathrm{~kg} / \mathrm{m}^{2}\right)$.

The study included 4 patients visits to the physician: V1 - entry visit, V2, V3, V4 - follow-up visits 4, 12 and 24 weeks after the entry visit. At the first visit, the previous AHT was discontinued and the fixed-dose combination of lisinopril $10 \mathrm{mg}+$ amlodipine $5 \mathrm{mg}$ + rosuvastatin $10 \mathrm{mg}$ was prescribed to every patient. In the course of the study, the physician had the opportunity to intensify the lipid-lowering therapy by prescribing the fixed-dose combination of lisinopril $10 \mathrm{mg}+$ amlodipine $5 \mathrm{mg}+$ rosuvastatin $20 \mathrm{mg}$ in cases when the target low-density lipoproteins (LDL) of $\leq 2.5 \mathrm{mmol} / \mathrm{L}$ was not reached for the high-risk patientsafter 4 weeks of therapy (at Visit 2).

Initially and after the course therapy, all the patients underwent $24 \mathrm{~h} \mathrm{BP}$ monitoring, examination of the vessel wall elasticity, echocardiography and laboratory testing.

The $24 \mathrm{~h}$ BP monitoring was performed using the Spacelabs 90207 device (USA). During the daytime hours (from 7 to 23 o'clock), measurements were made every 15 min, during the night (from 23 to 7 o'clock) - every $30 \mathrm{~min}$. A special cuff was used to measure the BP in the patients with excessive body weight.

The PWV, AI and central aortic pressure were determined using the SphygmoCor device ${ }^{[23,24]}$.

In 2010, a group of Spanish researchers published modified SCORE scales for the calculation of vascular age for European countries with high and low cardiovascular disease level ${ }^{[25]}$. The method of vascular age calculation from these scales involves calculating the absolute cardiovascular risk (ACVR) from the standard SCORE scales and then comparing the percentage of ACVR with the age of the vessels from the modified SCORE scale. To perform these calculations, the following data are required: patient's gender, passport age, smoking status, levels of systolic BP and total cholesterol (TC).

Serum adipocytokines were determined by enzyme immunoassay using Mediagnost kits, leptin high sensitive (0.05-5 ng/mL) and BCM diagnostics adiponectin. Blood was drawn into a plastic test tube without a stabilizer. After centrifugation at $1000 \mathrm{RPM}$ for $10 \mathrm{~min}, 1 \mathrm{~mL}$ of serum was collected. Before the determination of leptin and adiponectin levels, the samples were stored at $-20^{\circ} \mathrm{C}$.

The insulin resistance was estimated by the homeostasis model assessment (HOMA) index. The study was conducted strictly on an empty stomach, after an 8-12 h period of night fasting. Plasma glucose and plasma insulin were studied. The glucose level was determined by the hexokinase method (La Roche reagents, La Roche automatic analyzer). Plasma insulin was determined by enzyme immunoassay [Insulin ELISA (Mercodia $\mathrm{AB}$, Sweden)]. The homeostasis model assessment of insulin resistance (HOMA-IR) index was calculated using the following formula: HOMA-IR = fasting glucose $(\mathrm{mmol} / \mathrm{L}) \times$ fasting insulin $(\mu \mathrm{IU} / \mathrm{mL}) / 22.5$. 
Table 1. Clinical and demographic characteristics of the cohort involved in the study

\begin{tabular}{ll}
\hline Indicator & \\
\hline Age, years & $55.2 \pm 6.5$ \\
BMI, $\mathrm{kg} / \mathrm{m}^{2}$ & $28.8 \pm 4.6$ \\
WC, cm & $86.9 \pm 13.0$ \\
Body fat \% & $38.7 \pm 7.6$ \\
\hline
\end{tabular}

BMI: body mass index; WC: waist circumference

Table 2. Changes in BP and HR after 6 months

\begin{tabular}{lll}
\hline Indicator & Initially & 6 months \\
\hline $\mathrm{SBP}, \mathrm{mmHg}$ & $156.2 \pm 10.0$ & $133.7 \pm 9.3^{\star}$ \\
$\mathrm{DBP}, \mathrm{mmHg}$ & $97.6 \pm 11.7$ & $79.6 \pm 4.5^{\star}$ \\
$\mathrm{HR}, \mathrm{bpm}$ & $74.6 \pm 7.7$ & $71.7 \pm 8.8$ \\
\hline
\end{tabular}

${ }^{\star} P<0.05$ vs. baseline; BP: blood pressure; SBP: systolic blood pressure; DBP: diastolic blood pressure; HR: heart rate

CRP was determined by immunoturbidimetric analysis [hs-CRP ELISA (Biomerica, USA)].

The statistical processing of the data obtained was carried out using the bio-medical data package statistical software package. The continuous quantitative initial and demographic characteristics were tested using the independent samples $t$-test. When the characteristic values were not normally distributed, the MannWhitney test was used. For the qualitative characteristics, either Fisher's exact test or $\chi^{2}$ test was applied depending on the number of observations in each cell of the contingency table. The data were presented in the form of $M \pm m$, where $M$ is the mean and $m$ is the standard error. To validate the changes before and after the treatment, Student's paired $t$-test was used.

The study design did not include randomization or calculation of the sample size since a limited number of patients with the characteristics required attend our outpatient clinic, considering this a limitation of the study, and thus an observer-dependent bias, carrying out the daily clinical practice according to clinical guidelines.

The study was conducted in accordance with the good clinical practice standards and the principles of the Helsinki Declaration. The study protocol was approved by the Regional Ethics Committee. Written informed consent was obtained from all the participants prior to their involvement in the study.

\section{RESULTS}

The clinical and demographic characteristics of the patients involved in the study are presented in Table 1.

Initially, the patients were treated with the following dual antihypertensive combinations: (1) ACEI + diuretic - 58.9\%; (2) ARB + diuretic - 23.1\%; (3) $\beta$-blocker (BB) + ARB - 3.6\%; (4) CA + ACEI - 3.6\%; (5) BB + ACEI - 3.6\%; (6) CA + diuretic - 1.8\%; (7) BB + diuretic - 1.8\%; (8) CA + ARB - 1.8\%; and (9) imidazoline receptor agonist + ACEI $-1.8 \%$.

At the time of entry into the study, statins were received by $21.4 \%$ (atorvastatin $40 \mathrm{mg}$ by $25.1 \%$ and $20 \mathrm{mg}$ by $41.6 \%$; rosuvastatin $5 \mathrm{mg}$ by $16.7 \%$ and $10 \mathrm{mg}$ by $8.3 \%$; simvastatin $20 \mathrm{mg}$ by $8.3 \%$ ). After 4 weeks of treatment, $23.2 \%$ of the patients needed doubling the dose of rosuvastatin.

According to the office BP measurements [Table 2], switching the patients from the dual antihypertensive combinations to the fixed-dose combination of lisinopril + amlodipine + rosuvastatin has resulted in a 
Table 3. Changes in the data of the $24 \mathrm{~h}$ BP monitoring after 6 months

\begin{tabular}{lll}
\hline Indicator & Initially & 6 months \\
\hline Day SBP, mmHg & $153.1 \pm 8.2$ & $128.6 \pm 17.1^{\star}$ \\
Day DBP, mmHg & $94.5 \pm 9.8$ & $73.9 \pm 6.0^{\star}$ \\
Day HR, bpm & $80.6 \pm 11.5$ & $76.3 \pm 13.2$ \\
Night SBP, mmHg & $138.9 \pm 26.3$ & $118.8 \pm 9.3^{\star}$ \\
Night DBP, mmHg & $82,2 \pm 11,8$ & $66.5 \pm 6.0^{\star}$ \\
Night HR, bpm & $68.2 \pm 12.9$ & $67.2 \pm 14.9$ \\
SBP time index - 24h, \% & $35.5 \pm 11.3$ & $21.0 \pm 8.3^{\star}$ \\
DBP time index - 24h, \% & $23.2 \pm 10.5$ & $16.2 \pm 6.8^{\star}$ \\
\hline
\end{tabular}

${ }^{\star} P<0.05$ vs. baseline; BP: blood pressure; SBP: systolic blood pressure; DBP: diastolic blood pressure; HR: heart rate

Table 4. Changes in the indicators of the vessel wall elasticity after 6 months

\begin{tabular}{lll}
\hline Indicator & \multicolumn{1}{c}{ Initially } & 6 months \\
\hline IMT, mm & $1.07 \pm 0.22$ & $1.03 \pm 0.2$ \\
Carotid-femoral PWV & $12.5 \pm 1.3$ & $10.7 \pm 1.4^{\star}$ \\
Central SBP, mmHg & $143.1 \pm 15.2$ & $131.4 \pm 8.5^{\star}$ \\
Augmentation index & $27.5 \pm 9.1$ & $23.5 \pm 9.2^{\star}$ \\
Vascular age, years & $60.8 \pm 10.0$ & $54.6 \pm 8.9^{\star}$ \\
\hline
\end{tabular}

${ }^{\star} P<0.05$ vs. baseline; IMT: intima-media thickness; PWV: pulse wave velocity; SBP: systolic blood pressure

decrease of $14.4 \%$ in systolic BP (SBP) and $18.4 \%$ in diastolic BP (DBP) $(P<0.05$ vs. baseline) in the absence of changes in the heart rate.

The data of the $24 \mathrm{~h} \mathrm{BP}$ monitoring have confirmed that switching to the fixed-dose combination of lisinopril + amlodipine + rosuvastatin makes it possible to reduce the average daily SBP by $16.1 \%$ and DBP by $21.8 \%$, the average nightly SBP by $14.5 \%$ and DBP by $19.1 \%(P<0.05$ vs. baseline). At the same time, in all the groups of the initial therapy, switching to the fixed-dose combination has been accompanied by a definite decrease in the BP variability [Table 3].

The rate of achieving the target $\mathrm{BP}$ of $<140 / 90 \mathrm{mmHg}$ with the use of the fixed-dose combination of lisinopril + amlodipine + rosuvastatin has been $73.2 \%$, whereas $23.2 \%$ of these patients have achieved a BP level of $<130 / 80 \mathrm{mmHg}$.

Table 4 shows the trends in the indicators characterizing the state of the arterial wall of the vessels belonging to the elastic or muscular type, as well as amortizing vessels, after switching the patients to the fixed-dose combination of lisinopril + amlodipine + rosuvastatin: there has been a decrease of $14.7 \%$ in the PWV $(P<0.05)$, $14.4 \%$ in the augmentation index $(P<0.05)$ and $8.1 \%$ in the CBP $(P<0.05)$, which has reduced the vascular age by $10.2 \%(P<0.05)$.

The fixed-dose combination therapy of lisinopril + amlodipine + rosuvastatin provides favorable performance of the lipid metabolism indicators: there has been a decrease of $29.4 \%$ in the TC $(P<0.05)$, a decrease of $31.9 \%$ in the triglycerids $(P<0.05)$, a decrease of $38.1 \%$ in LDL $(P<0.05)$, and an increase of $10.5 \%$ in high-density lipoproteins $(P<0.05)$. The rate of achieving the LDL target of $\leq 2.5 \mathrm{mmol} / \mathrm{L}$ with the use of the fixed-dose combination of lisinopril + amlodipine + rosuvastatin has been $71.4 \%$. After switching to the fixed-dose combination, all the groups have shown positive trends in the studied biochemical indicators characterizing the functions of the liver and kidneys, although it has not been statistically significant [Table 5].

Switching the patients to the fixed-dose combination of lisinopril + amlodipine + rosuvastatin has been 
Table 5. Changes in the studied biochemical indicators after 6 months

\begin{tabular}{lll}
\hline Indicator & Initially & $\mathbf{6}$ months \\
\hline $\mathrm{TC}, \mathrm{mmol} / \mathrm{L}$ & $6.4 \pm 1.0$ & $4.5 \pm 1.0^{\star}$ \\
$\mathrm{HDL}, \mathrm{mmol} / \mathrm{L}$ & $1.2 \pm 0.3$ & $1.3 \pm 0.3^{\star}$ \\
$\mathrm{TG}, \mathrm{mmol} / \mathrm{L}$ & $2.5 \pm 0.7$ & $1.7 \pm 0.5^{\star}$ \\
$\mathrm{LDL}, \mathrm{mmol} / \mathrm{L}$ & $4.1 \pm 1.1$ & $2.5 \pm 1.1^{\star}$ \\
$\mathrm{ALT}, \mathrm{u} / \mathrm{L}$ & $27.9 \pm 10.8$ & $24.8 \pm 7.8$ \\
$\mathrm{AST}, \mathrm{u} / \mathrm{L}$ & $29.3 \pm 8.1$ & $24.3 \pm 6.8$ \\
Creatinine, $\mu \mathrm{mol} / \mathrm{L}$ & $81.6 \pm 9.5$ & $72.7 \pm 8.3$ \\
\hline
\end{tabular}

${ }^{\star} P<0.05$ vs. baseline; TC: total cholesterol; HDL: high-density lipoproteins; TG: triglycerids; LDL: low-density lipoproteins; ALT: alanine transaminase; AST: aspartate aminotransferase

Table 6. Changes in the indicators of carbohydrate metabolism after 6 months

\begin{tabular}{lll}
\hline Indicator & Initially & 6 months \\
\hline Fasting plasma glucose, mmol/L & $7.0 \pm 1.3$ & $6.2 \pm 1.0^{\star}$ \\
Insulin, $\mu \mathrm{IU} / \mathrm{mL}$ & $15.5 \pm 5.9$ & $13.8 \pm 6.3^{\star}$ \\
$\mathrm{HOMA}$ index, $\mu \mathrm{IU} / \mathrm{mL}$ & $4.8 \pm 2.1$ & $3.7 \pm 1.5^{\star}$ \\
\hline
\end{tabular}

$\star P<0.05$ vs. Baseline; HOMA: homeostasis model assessment

Table 7. Trends in the adipokin levels after 6 months

\begin{tabular}{lcl}
\hline Indicator & Initially & 12 weeks \\
\hline Leptin, $\mathrm{ng} / \mathrm{mL}$ & $16.3 \pm 7.7$ & $14.6 \pm 7.9^{\star}$ \\
Adiponectin, $\mu \mathrm{g} / \mathrm{mL}$ & $6.9 \pm 2.6$ & $7.6 \pm 2.8^{\star}$ \\
us-CRP, $\mathrm{mg} / \mathrm{L}$ & $3.1 \pm 1.6$ & $2.7 \pm 1.5^{\star}$ \\
\hline
\end{tabular}

$\star P<0.05$ vs. baseline; us-CRP: ultra-sensitive C-reactive protein

Table 8. Changes in the anthropometric indicators after 6 months

\begin{tabular}{lll}
\hline Indicator & \multicolumn{1}{c}{ Initially } & 6 months \\
\hline Weight, $\mathrm{kg}$ & $82.8 \pm 9.2$ & $81.6 \pm 8.4$ \\
$\mathrm{BMI}, \mathrm{kg} / \mathrm{m}^{2}$ & $28.8 \pm 3.5$ & $28.4 \pm 3.4$ \\
WC, cm & $86.9 \pm 13.0$ & $83.1 \pm 11.5$ \\
$\mathrm{HC}, \mathrm{cm}$ & $104.1 \pm 13.6$ & $100.1 \pm 13.5$ \\
Body fat \% & $38.7 \pm 7.7$ & $37.7 \pm 8.2$ \\
\hline
\end{tabular}

BMI: body mass index; WC: waist circumference; HC: hip circumference

accompanied by an improvement in the carbohydrate metabolism indicators [Table 6]: a decrease of $11.1 \%$ in the insulin $(P<0.05)$ and $22.9 \%$ in the HOMA index $(P<0.05)$.

Particular attention should be paid to the possibility of the fixed-dose combination of lisinopril + amlodipine + rosuvastatin to have a positive effect on the level of key adipokines: the average leptin level has become lower by $10.7 \%(P<0.05)$, us-CRP - by $11.8 \%(P<0.05)$ and the adiponectin level has increased by $9.9 \%(P<0.05)$ [Table 7 .

There have been no statistically significant changes in the anthropometric indicators revealed during the study [Table 8].

\section{DISCUSSION}

The importance of assessing the possibility of further angioprotection with the use of the fixed-dose combination of lisinopril + amlodipine + rosuvastatin in patients with AH undergoing a two-component 
AHT is confirmed by the initiation of The LOW CBP study (Targeted LOWering of CBP in patients with hypertension: a randomised controlled trial) and the findings that the combinations of perindopril + amlodipine, valsartan + amlodipine, azelnidipine + olmesartan have a more pronounced positive effect on aortic elasticity than the combinations of atenolol + hydrochlorothiazide, atenolol + amlodipine, olmesartan + hydrochlorothiazide ${ }^{[12-13]}$. We must also add the trend to a "tighter" control of BP, lipids and inflammation ${ }^{[1,2,18-21]}$. Therefore, it is appropriate to try to solve these problems using the fixed-dose combination of lisinopril + amlodipine + rosuvastatin which is also able to perform the task of a multitarget pharmacotherapy.

First of all, it should be noted that switching patients from different two-component antihypertensive combinations (mainly the renin-angiotensin-aldosterone system blockers and diuretics) therapy which they underwent for at least 6 months to the fixed-dose combination of lisinopril + amlodipine + rosuvastatin has provided the achievement of the target BP in 7 out of 10 patients, given the fact that the study did not involve the use of maximum doses of antihypertensive drugs in this combination. This is apparently explained by an enhancement of the hypotensive potential due to the statins ${ }^{[2]}$. The decrease in BP has been confirmed by the data of the $24 \mathrm{~h}$ BP monitoring, and all the groups of the initial therapy have shown a positive effect of the fixed-dose combination of lisinopril + amlodipine + rosuvastatin on the BP variability, which can be considered as an important component in the correction of systemic hemodynamic atherothrombotic syndrome ${ }^{[27]}$.

The improved control of BP after the use of the fixed-dose combination of lisinopril + amlodipine + rosuvastatin and the lipid target achievement in 7 out of 10 patients has been naturally accompanied by positive changes in the indicators of vessel wall elasticity (PWV, CBP, AI, vascular age). These favorable changes should be explained not only by the achievement of the BP and lipid targets, but also the positive effect on adipokines (leptin and adiponectin) and low-intensity non-infectious inflammation (us-CRP), which represents an additional factor of angioprotection ${ }^{[28-30]}$.

It is important to emphasize that the use of rosuvastatin in combination with lisinopril and amlodipine has been accompanied by a decrease in the insulin resistance and a positive effect on the carbohydrate metabolism, which removes all the questions about the diabetogenic potential of statins when used in this therapy option.

Thus, it can be said that switching patients from two-component antihypertensive combinations to the fixed-dose combination of lisinopril + amlodipine + rosuvastatin provides better control of BP, lipids, angioprotection and reduction of inflammation in combination with improved carbohydrate metabolism and balance of adipokines.

\section{DECLARATIONS}

\section{Authors' contributions}

Conceived of the study: Nedogoda SV

Recruitment and clinical assessment, statistical analysis: Chumachek EV, Ledyaeva AA, Tsoma VV, Salasyuk AS, Smirnova VO, Hripaeva VY, Palashkin RV, Popova EA

Drafted the initial version of the report: Chumachek EV, Salasyuk AS

Revision and editing of the report: all authors

\section{Availability of data and materials}

Reader can ask or mail to corresponding author for materials.

\section{Financial support and sponsorship}

The authors state that there is no need to disclose financial support with respect to this publication. 


\section{Conflicts of interest}

All authors declared that there are no conflicts of interest.

\section{Ethical approval and consent to participate}

The study protocol was approved by the Local Ethics Committee of the Volgograd Medical University. Each patient was informed about the study and gave their consent.

\section{Consent for publication}

Not applicable.

\section{Copyright}

(c) The Author(s) 2018.

\section{REFERENCES}

1. Whelton PK, Carey RM, Aronow WS, Casey DE Jr, Collins KJ, et al. 2017 ACC/AHA/AAPA/ABC/ACPM/AGS/APhA/ASH/ ASPC/NMA/PCNA guideline for the prevention, detection, evaluation, and management of high blood pressure in adults: a report of the American College of Cardiology/American Heart Association Task Force on clinical practice guidelines. J Am Coll Cardiol 2018;71:e127-248.

2. Catapano AL, Graham I, De Backer G, Wiklund O, Chapman MJ, et al. 2016 ESC/EAS guidelines for the management of dyslipidemias. Eur Heart J 2016;37:2999-3058.

3. Nemcsik J, Cseprekál O, Tislér A. Measurement of arterial stiffness: a novel tool of risk stratification in hypertension. Adv Exp Med Biol 2017;956:475-88.

4. Dahlöf B, Sever PS, Poulter NR, Wedel H, Beevers DG, et al. Prevention of cardiovascular events with an antihypertensive regimen of amlodipine adding perindopril as required versus atenolol adding bendroflumethiazide as required, in the Anglo-Scandinavian Cardiac Outcomes Trial-blood pressure lowering arm (ASCOT-BPLA): a multicentre randomised controlled trial. Lancet 2005;366:895-906.

5. Manisty CH, Zambanini A, Parker KH, Davies JE, Francis DP, et al. Differences in the magnitude of wave reflection account for differential effects of amlodipine- versus atenolol-based regimens on central blood pressure: an Anglo-Scandinavian Cardiac Outcome Trial substudy. Hypertension 2009;54:724-30.

6. Chen X, Huang B, Liu M, Li X. Effects of different types of antihypertensive agents on arterial stiffness: a systematic review and metaanalysis of randomized controlled trials. J Thorac Dis 2015;7:2339-47.

7. Morgan T, Lauri J, Bertram D, Anderson A. Effect of different antihypertensive drug classes on central aortic pressure. Am J Hypertens 2004; $17: 118-23$.

8. Mackenzie IS, McEniery CM, Dhakam Z, Brown MJ, Cockcroft JR, et al. Comparison of the effects of antihypertensive agents on central blood pressure and arterial stiffness in isolated systolic hypertension. Hypertension 2009;54:409-13.

9. Elliott WJ, Childers WK. Should $\beta$ blockers no longer be considered first-line therapy for the treatment of essential hypertension without comorbidities? Curr Cardiol Rep 2011;13:507-16.

10. Hirata K, Vlachopoulos C, Adji A, O'Rourke MF. Benefits from angiotensin-converting enzyme inhibitor 'beyond blood pressure lowering': beyond blood pressure or beyond the brachial artery? J Hypertens 2005;23:551-6.

11. London GM, Pannier B, Guerin AP, Marchais SJ, Safar ME, et al. Cardiac hypertrophy, aortic compliance, peripheral resistance, and wave reflection in end-stage renal disease. Comparative effects of ACE inhibition and calcium channel blockade. Circulation 1994;90:2786-96.

12. Dhakam Z, McEniery CM, Yasmin, Cockcroft JR, Brown MJ, et al. Atenolol and eprosartan: differential effects on central blood pressure and aortic pulse wave velocity. Am J Hypertens 2006;19:214-9.

13. Mahmud A, Feely J. Favourable effects on arterial wave reflection and pulse pressure amplification of adding angiotensin II receptor blockade in resistant hypertension. J Hum Hypertens 2000;14:541-6.

14. Williams B, Lacy PS, Thom SM, Cruickshank K, Stanton A, et al. Differential impact of blood pressure-lowering drugs on central aortic pressure and clinical outcomes: principal results of the Conduit Artery Function Evaluation (CAFE) study. Circulation 2006;113:1213-25.

15. Boutouyrie P, Achouba A, Trunet P, Laurent S; EXPLOR Trialist Group. Amlodipine-valsartan combination decreases central systolic blood pressure more effectively than the amlodipine-atenolol combination: the EXPLOR study. Hypertension 2010;55:1314-22.

16. Matsui Y, Eguchi K, O’Rourke MF, Ishikawa J, Shimada K, et al. Association between aldosterone induced by antihypertensive medication and arterial stiffness reduction: the J-CORE study. Atherosclerosis 2011;215:184-8.

17. Guerin AP, Blacher J, Pannier B, Marchais SJ, Safar ME, et al. Impact of aortic stiffness attenuation on survival of patients in end-stage renal failure. Circulation 2001;103:987-92.

18. Ridker PM. Clinical application of C-reactive protein for cardiovascular disease detection and prevention. Circulation 2003;107:363-9. 
19. Yusuf S, Bosch J, Dagenais G, Zhu J, Xavier D, et al. Cholesterol lowering in intermediate-risk persons without cardiovascular disease. N Engl J Med 2016;374:2021-31.

20. Ridker PM, Danielson E, Fonseca FA, Genest J, Gotto AM Jr, et al. Rosuvastatin to prevent vascular events in men and women with elevated C-reactive protein. N Engl J Med 2008;359:2195-207.

21. Roberts ER, Green D, Kadam UT. Chronic condition comorbidity and multidrug therapy in general practice populations: a crosssectional linkage study. BMJ Open 2014;4:e005429.

22. American Diabetes Association. Standards of medical care in diabetes 2017: summary of revisions. Diabetes Care 2017;40:S4-5.

23. Doupis J, Papanas N, Cohen A, McFarlan L, Horton E. Pulse wave analysis by applanation tonometry for the measurement of arterial stiffness. Open Cardiovasc Med J 2016;31:188-95.

24. Van Bortel LM, De Backer T, Segers P. Standardization of arterial stiffness measurements make them ready for use in clinical practice. Am J Hypertens 2016;29:1234-6.

25. Cuende JI, Cuende N, Calaveras-Lagartos J. How to calculate vascular age with the SCORE project scales: a new method of cardiovascular risk evaluation. Eur Heart J 2010;31:2351-8.

26. Briasoulis A, Agarwal V, Valachis A, Messerli FH. Antihypertensive effects of statins: a meta-analysis of prospective controlled studies. J Clin Hypertens (Greenwich) 2013;15:310-20.

27. Kario K. Orthostatic hypertension-a new haemodynamic cardiovascular risk factor. Nat Rev Nephrol 2013;9:726-38.

28. Ionescu DD; PREFER Investigators. Antihypertensive efficacy of perindopril 5-10 mg/day in primary health care: an open-label, prospective, observational study. Clin Drug Investig 2009;29:767-76.

29. Fennessy PA, Campbell JH, Mendelsohn FA, Campbell GR. Angiotensin-converting enzyme inhibitors and atherosclerosis: relevance of animal models to human disease. Clin Exp Pharmacol Physiol 1996;23:S30-2.

30. Koz C, Baysan O, Yokusoglu M, Uzun M, Yildirim M, et al. The effects of perindopril on aortic elasticity and inflammatory markers in hypertensive patients. Med Sci Monit 2009;15:PI41-5. 